\title{
Lisina e metionina + cistina digestíveis sobre o desempenho e qualidade de ovos de poedeiras comerciais: Revisão
}

\author{
$\underline{\text { Carla Heloisa de Faria Domingues }}^{1 *}, \underline{\text { Sarah Sgavioli }}^{1}$, Maria Fernanda Ferreira Menegucci

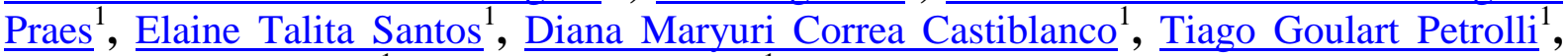 \\ $\underline{\text { Karina Ferreira Duarte }}^{1}$, Otto Mack Junqueira ${ }^{1}$ \\ ${ }^{I}$ Departamento de Zootecnia, Universidade Estadual Paulista FCAV/UNESP, Jaboticabal, São Paulo, Brasil \\ *Autor para correspondência, email: carlafariadomingues@hotmail.com
}

\begin{abstract}
RESUMO. A responsabilidade do sucesso alcançado pela avicultura no país se deve, em grande parte, aos avanços obtidos dentro da área de nutrição. Muitos estudos têm surgido objetivando melhorar os parâmetros zootécnicos e especialmente de produção de ovos, manipulando - se os níveis nutricionais das dietas para poedeiras, a fim de adequar as suas exigências para a obtenção de maiores produções. A metionina e a lisina são consideradas o primeiro e o segundo aminoácidos limitantes para as aves, respectivamente. Portanto, a suplementação na dieta de maneira correta e fundamental para garantir os aspectos de mantença, crescimento e produção das aves.
\end{abstract}

Palavras chave: aminoácido, aves, muda, recuperação corporal

\section{Lysine and methionine + cystine on performance and egg quality of laying hens: Review}

\begin{abstract}
Poultry industry success achieved in Brazil is due to nutrition advances. Many studies have emerged aiming to improve birds performance and especially egg production by manipulating the nutrient levels of diets in order to comply the requirements for obtaining higher yields. Methionine and lysine are considered as the first and second limiting amino acid for birds, respectively. Therefore, the correct diet supplementation is necessary to ensure the laying hens aspects of maintenance, growth and production.
\end{abstract}

Keywords: amino acids, birds, body recovery, molt

\section{Introdução}

As linhagens de poedeiras utilizadas para a produção de ovos possuem alto potencial genético e podem ser utilizadas além de um ciclo de produção, através da indução da muda, que pode ser definida como um conjunto de práticas realizadas com a finalidade de provocar estresse nas aves, que levará a uma pausa na produção e muda de penas parcial (Roland \& Brake, 1982). O objetivo desta técnica é fazer o sistema reprodutivo da ave repousar por um período, regenerar a capacidade produtiva e aumentar a vida útil da poedeira por mais 25 a 30 semanas, além de melhorar a qualidade dos ovos e reduzir o nível de perdas com baixa qualidade de casca (Cotta, 1997).
Alguns fatores como necessidade de melhoria da qualidade do ovo de aves velhas, custos de formação das frangas de reposição, situação de oferta, preços de ovos no mercado consumidor, problemas de sazonalidade de demanda de ovos, entre outros, podem influenciar nessa decisão.

A muda ocorre naturalmente em aves e representa o período em que acontecem mudanças no comportamento de ingestão de alimentos, com redução ou cessação das suas funções reprodutivas e substituição da plumagem (Cotta, 1997). Normalmente, este processo ocorre em foto período decrescente, devido à menor quantidade de luz que incide sobre os olhos das aves. A luminosidade tem como função provocar um estímulo, que é conduzido pelo sistema nervoso até o cérebro e a glândula pituitária. Esta 
glândula libera o hormônio luteinizante, que por sua vez determina a ovulação (Lana et al., 2001). A muda induzida permite que o plantel de aves cesse a postura em um período estabelecido, sincronizando assim a produção de ovos no segundo ciclo de postura.

Existe uma grande diversidade de métodos que vão desde a restrição alimentar, de água e luz, à utilização de agentes químicos (óxido de zinco), associados à alteração de foto periodismo, gerando mudanças em várias funções endócrinas, que serão os determinantes do mecanismo da muda. Existem também técnicas que são menos utilizadas, provavelmente devido à falta de praticidade, porém, com resultados satisfatórios, que incluem a utilização de hormônios tais como a progesterona (Shafer et al., 1996) e a tiroxina (T4) da tireóide (Kuenzel et al., 2005). A retirada da ração dos comedouros durante 10 a 12 dias é o método mais simples e, portanto, o mais utilizado, apesar de ser agressivo e causar estresse às aves (Cotta, 1997).

Uma produtividade satisfatória durante o segundo ciclo de produção, só é atingida quando as aves têm condições nutricionais adequadas, para garantir uma boa recuperação dos componentes corporais e retorno rápido à produção de ovos (Mendonça Jr \& Lima, 1999). Dentre os nutrientes requeridos pela galinha para o período de descanso, destacam-se a proteína, em especial os aminoácidos sulfurados. Dos mais de vinte aminoácidos constituintes das proteínas, praticamente a metade destes são considerados aminoácidos essenciais, devendo ser fornecidos à dieta, e o restante, os não essenciais podem ser produzidos pelas aves em quantidades suficientes pelo organismo. Mendonça (1996) comenta que para o máximo desempenho produtivo de galinhas poedeiras é necessário aporte protéico baseado nas exigências em aminoácidos essenciais, particularmente lisina e metionina + cistina. A deficiência de lisina provoca redução na síntese protéica, sendo importante para a formação da proteína do ovo e da proteína corporal das aves (Hiramoto et al., 1990). Os níveis de aminoácidos sulfurados podem influenciar na qualidade de ovos, dentre os parâmetros internos que são influenciados, destacam-se a unidade de Haugh e o índice de albúmen (Bertechini et al., 1995).

Diante do contexto exposto, a presente revisão tem como objetivo, abordar os efeitos da utilização de lisina e metionina+cistina sobre o desempenho e qualidade dos ovos e poedeiras comerciais.

\section{Muda}

As poedeiras comerciais iniciam a sua fase produtiva por volta de $18-20$ semanas de idade, atingindo o pico de postura em torno de 24 semanas de idade (Cotta, 1997), com o avançar da idade da poedeira, ao final do primeiro ciclo de postura, que ocorre por volta de 70 semanas, a casca dos ovos perde espessura e resistência, justamente quando o peso dos ovos é maior. Esse é um dos principais motivos para a indução da muda em galinhas poedeiras, sendo uma prática muito frequente em granjas comerciais, o qual resultará em cessação na produção de ovos, involução do trato reprodutivo e perda de penas (Roland \& Brake, 1982).

Os órgãos reprodutivos são orientados pelo eixo hipotalâmico-hipófisário-gonadal (Macari \& Furlan, 1993); portanto a diminuição no substrato circulante decorrente das restrições alimentares, principalmente de aminoácidos, proporciona redução na secreção dos hormônios gonadotróficos, levando à atrofia do ovário e do oviduto como é requerido no processo de muda. Os folículos em maturação hierárquica sofrem atresia e o material da gema é reabsorvido, causando uma diminuição no peso do ovário. A redução do peso do ovário é inicialmente independente da duração do jejum e da taxa de perda de peso corporal. Após a perda de $25 \%$ do peso corporal, o ovário está completamente regredido (Bertechini \& Geraldo, 2005).

As técnicas de muda variam amplamente em métodos. A estratégia tradicional utiliza o jejum por um determinado período de tempo (Cotta, 1997), ou até atingir uma perda de peso corporal próxima de $30 \%$, com ou sem a restrição de água. Nos primeiro dias, a produção de ovos declina até suspensão completa da postura de 4 a 5 dias do início do jejum (Silva \& Santos, 2000). Apesar do método de jejum ser amplamente utilizado pelos produtores devido à facilidade de aplicação e ao seu custo benefício, causa estresse nas aves e altos índices de mortalidade. Portanto, esse método tem sido questionado em relação aos aspectos relacionados com o bem estar da ave (Webster, 2003).

Segundo Biggs et al. (2003), a indução das poedeiras a muda, utilizando ração comercial com níveis de 2.000 a 2.800 ppm de óxido de zinco, constitui o único método alternativo aos 
métodos agressivos para as aves. Neste método as aves não passam por privação de alimento, no entanto, o consumo de ração das aves alimentadas com óxido de zinco é reduzido devido à palatabilidade do alimento. Portanto, este método promove a perda de peso corpóreo desejada, não havendo grandes mortalidades (Berry \& Brake, 1985). Os métodos de muda induzida pela utilização de ração com deficiência em sódio ou com altos níveis de zinco, não têm sido utilizados substancialmente em programas comerciais por serem caros e devido aos resultados das pesquisas não serem conclusivos (Biggs et al., 2003).

Albuquerque et al. (1999) trabalhando com diferentes métodos de muda (jejum alimentar, dietas com excesso de zinco, com baixo sódio e elevado iodo dietético), concluíram que os métodos de jejum alimentar e o de fornecimento de dieta com excesso de zinco, durante a muda, propiciaram os melhores resultados de desempenho das aves no segundo ciclo de produção. No entanto, Breeding et al. (1992) em estudo com a inclusão de $2.800 \mathrm{ppm}$ de óxido de zinco em dieta com nível de $0,08 \%$ de cálcio, observaram uma menor perda de peso do duodeno de poedeiras por um período de 14 dias, quando comparado às aves que receberam um tratamento controle (jejum alimentar), indicando, portanto, uma ineficiência quanto à perda de peso do trato gastrointestinal, para as aves submetidas ao método com adição de óxido de zinco.

\section{Período de descanso}

Uma produtividade satisfatória durante o segundo ciclo de produção, só é atingida quando as aves têm condições nutricionais adequadas para garantir uma boa recuperação dos componentes corporais e retorno rápido à produção de ovos (Mendonça Jr \& Lima, 1999). Dentre os nutrientes requeridos pela galinha para o período de descanso, destacam-se a proteína, em especial os aminoácidos sulfurados. Depois da energia, os ingredientes protéicos são os mais caros e um dos principais nutrientes presentes na dieta, cuja eficiência de utilização depende da quantidade, da composição e da digestibilidade de seus aminoácidos, os quais são exigidos em níveis específicos pelas aves (Dale, 1994).

A formulação de rações com base em aminoácidos digestíveis, que são definidos como os aminoácidos que são realmente absorvidos pelo trato digestivo, é um novo conceito em nutrição na avicultura, pois com a inclusão de aminoácidos sintéticos nas dietas, torna-se possível a redução da inclusão de alimentos protéicos como a soja, ou até mesmo a substituição parcial ou total deste, por fontes de proteína alternativas, como as farinhas de origem animal, permitindo a formulação de uma ração que atenda os níveis de aminoácidos, a um custo inferior.

Muitos pesquisadores têm reportado que a adição de metionina industrializada em dietas com baixo teor de proteína promove resultados econômicos satisfatórios (Combs, 1964, Harms \& Miles, 1988, Waldroup \& Hellwig, 1995). Segundo Harms \& Russell (1993), os níveis de aminoácidos na ração, especialmente aqueles que compõem os aminoácidos sulfurados são importantes, pois podem influenciar diretamente o tamanho dos ovos produzidos, durante o segundo ciclo de produção. Andrews et al. (1987) relataram que o fornecimento de dieta durante $\mathrm{o}$ período de descanso, contendo $0,65 \%$ de metionina+cistina digestíveis, determinou maior produção de ovos, em relação a uma dieta com $0,60 \%$ de metionina+cistina digestíveis. Entretanto, como evidenciado nos estudos de Calderon \& Jensen (1990), o aumento na produção de ovos em resposta ao aumento nos níveis de metionina+cistina digestíveis, também dependem do nível de proteína da dieta. Os mesmos autores determinaram que, em dietas com 13, 16 e $19 \%$ de proteína, as exigências de metionina+cistina ficaram na faixa de $0,48 \%$ a $0,55 \%, 0,59 \%$ a $0,61 \%$ e $0,60 \%$ a $0,70 \%$, respectivamente. Sohail et al. (2002) ao conduzirem quatro experimentos, com o objetivo de avaliar os diferentes níveis de suplementação de lisina, isoleucina, treonina e triptofano, observaram que as aves responderam à uma inclusão de aminoácidos sulfurados $(0,65$ a $0,81 \%)$, dentro do período de uma semana.

O melhor peso e a melhor produção de ovos foram observados mediante a inclusão de $0,81 \%$. Mendonça Jr \& Lima (1999), estudando o efeito de rações contendo dois níveis de proteína $(16,5 \%$ e $14,5 \%)$ e cinco teores suplementares de metionina $(0 \%, 0,025 \%, 0,050 \%, 0,075 \%$ e $0,100 \%$ ), durante o período de descanso, observaram que o aumento dos níveis dos aminoácidos sulfurados totais, determinou maior peso do ovo, sem aumentar a produção de ovos. Por outro lado, devido o aumento no peso dos ovos, ocorreu uma piora na qualidade de casca. 


\section{Efeitos da lisina na ração sobre o desempenho de poedeiras}

Os aminoácidos limitantes são aqueles que estão presentes na ração em concentração menor do que a exigida para o máximo crescimento. Para as aves alimentadas com ração a base de milho e farelo de soja, a ordem de limitação é a metionina seguida da lisina e treonina. Pode estar limitante em uma ração um ou mais aminoácidos ao mesmo tempo; porém, a ordem de limitação pode variar de acordo com os ingredientes utilizados (Andriguetto et al., 2003). A lisina é considerada um aminoácido fisiologicamente essencial para mantença, crescimento e produção das aves, tendo como principal função a síntese de proteína muscular. Ela é considerada essencial porque é sintetizada pelo organismo em pequenas quantidades, que não atendem a necessidade do animal, sendo necessário a ingestão de proteína intacta do alimento ou de fontes sintéticas como a L-lisina HCl. Hiramoto et al. (1990), trabalhando com poedeiras, observaram que a deficiência de lisina provocou redução na síntese protéica, e que este aminoácido é importante para a formação da proteína do ovo e da proteína corporal das aves.

Rostagno et al. (2005) recomendam 0,66\% de lisina digestível para poedeiras semi-pesadas, em todo ciclo de produção. Por outro lado, Rostagno et al. (2011) recomendam $0,63 \%$ de lisina digestível para poedeiras semi-pesadas com 70 semanas de idade, enquanto que o manual de criação da Hy-line W36, apresenta uma exigência de lisina que varia de 0,81 a $0,89 \%$ no período de pico de postura. Segundo Jardim Filho et al. (2010), dietas contendo 0,75 e $0,77 \%$ de lisina digestível proporcionam melhor consumo e balanço de nitrogênio nas aves.

Pastore et al. (2015), recomendam o consumo diário de $690 \mathrm{mg} \mathrm{ave}^{-1}$ de lisina digestível para poedeiras de 60 a 76 semanas de idade. Segundo Nunes et al. (2015), para maximizar a qualidade interna dos ovos, recomenda-se o nível dietético de 0,$884 ; 0,868$ e $0,903 \%$ de lisina digestível para unidade Haugh, índice de albúmem e índice gema, respectivamente. De maneira geral, a recomendação para poedeiras durante a fase de cria, recria e produção de ovos é feita pelas empresas responsáveis pelas linhagens utilizadas, de modo que não raramente são superiores às recomendações propostas em diversas tabelas de exigências nutricionais.

\section{Efeitos da metionina + cistina na ração sobre o desempenho produtivo de poedeiras}

A metionina tem um papel importante no metabolismo de fosfolipídios e sua deficiência é conhecida por causar prejuízos renais e hepáticos. Entretanto, a administração de doses excessivas deste aminoácido representa risco de fígado gorduroso (Parr \& Summers, 1991).

A cistina é um aminoácido glicogênico, não essencial, produzido a partir da metionina no organismo que interage com a cisteína, em uma reação de transformação mútua do tipo oxiredução. A ingestão de cistina ou cisteína pode reduzir as necessidades nutricionais de metionina. A cistina é necessária para a formação da pele, penas e pêlos. Além do mais, é sabido que estimula o sistema hematopoiético e promove a formação de glóbulos brancos e vermelhos, contribuindo com o processo de cicatrização, diminuindo a dor causada pela inflamação e fortalecendo a formação de tecido conjuntivo. $\mathrm{O}$ enxofre necessário para a biossíntese da cisteína provém do aminoácido essencial metionina.

Togashi et al. (2002) conduziram um experimento utilizando 120 galinhas poedeiras semi-pesadas, da linhagem comercial Isa Brown, alimentadas com rações contendo levedura de cana-de-açúcar, visando a determinação das exigências nutricionais de metionina + cistina. Os tratamentos consistiram de uma ração basal, suplementada com cinco níveis de DL-metionina, a fim de se obterem rações com 0,$45 ; 0,50 ; 0,55$; 0,60 e $0,65 \%$ de metionina+cistina. Para a maximização da produção de ovos e consumo de ração, as exigências foram estimadas em $0,565 \mathrm{e}$ $0,569 \%$ de metionina+cistina, respectivamente.

\section{Efeitos de níveis de metionina + cistina sobre a qualidade dos ovos de poedeiras.}

A avicultura de postura comercial registra perdas econômicas significativas devido aos problemas na qualidade dos ovos, que aumenta com o avanço da idade das aves. Além da característica da casca, também as características internas apresentam grande valor, quando se trata de qualidade de ovos. A composição química do albúmen do ovo é bastante estável e difícil de ser modificada nutricionalmente. Isto se deve em função de seus componentes serem segregados pelas células epiteliais do oviduto. Assim, uma mudança nos níveis nutricionais da ração, não modifica de forma substancial a composição do 
albúmen, porém pode alterar a relação gema/albúmen (Mateos, 1991). Leeson et al. (2001) descrevem que o ovo contém $12 \%$ de proteína bruta, sendo que $42 \%$ da gema, $55 \%$ do albúmen e $3 \%$ da casca são proteínas e que estas moléculas possuem perfis de aminoácidos diferentes.

Diversas pesquisas realizadas com o objetivo de avaliar e correlacionar medidas dos componentes internos do ovo, como atributos de sua qualidade interna, sugeriram algumas medidas, e dentre elas, encontra-se a unidade Haugh (Fernandes et al., 1983). A medida de unidade Haugh é baseada em uma relação entre a altura do albúmen e o peso do ovo, muito utilizada como medida de qualidade interna dos ovos. Quanto maiores forem os valores encontrados para este parâmetro, melhor será a qualidade interna do ovo. Bertechini et al. (1995) trabalhando com poedeiras comerciais semipesadas na fase de pico de produção, verificaram que o aumento de aminoácidos sulfurosos totais na ração $(0,545 ; 0,595 ; 0,645 ; 0,695$ e $0,745 \%)$ provocaram redução linear nos valores de unidade Haugh $(100,6 ; 97,5 ; 96,1 ; 95,7$ e 93,5).

\section{Aspectos importantes da utilização da lisina e da metionina + cistina sobre a recuperação corporal das aves}

Durante o processo de muda, podem ocorrer elevadas taxas de mortalidade e distúrbios fisiológicos, como redução do peso corporal, dos órgãos digestórios e reprodutivos. Estas alterações influenciam o funcionamento do organismo das aves, podendo comprometer o desempenho produtivo no segundo ciclo de produção. Portanto, durante $\mathrm{o}$ período de descanso, o fornecimento de um aporte de nutrientes, em especial de aminoácidos, é de extrema importância para a recuperação corporal das aves. O excesso ou a falta de aminoácidos pode causar uma diminuição na eficiência de utilização dietética e diminuir o consumo de alimento e de crescimento pelas aves (Rodrigueiro et al., 2000).

A lisina além de influenciar no desempenho produtivo (Prochaska et al., 1996), também está relacionada com a síntese de proteína corporal, especialmente na formação do tecido ósseo e muscular (Silva \& Santos, 2000).

A metionina e a cistina são aminoácidos glicogênicos, utilizados na formação do glicogênio do fígado e músculo pelo processo da gliconeogênese; portanto afetam diretamente na recuperação corporal das aves.

\section{Considerações Finais}

A correta suplementação de lisina e a metionina+cistina digestíveis são fundamentais para poedeiras, pois influencia no desempenho, qualidade dos ovos e recuperação corporal das aves.

\section{Referências Bibliográficas}

Albuquerque, R., Mendonça Jr, C. X., Ghion, E. \& Lma, C. G. (1999). Efeito de diferentes métodos de descanso forçado sobre o desempenho de poedeiras. Brazilian Journal of Veterinary Research and Animal Science, 36, 159-163.

Andrews, D., Berry, W. \& Brake, J. (1987). Effect of lighting program and nutrition on reproductive performance of molted Single Comb White Leghorn hens. Poultry Science, 66, 1298-1305.

Andriguetto, J. M., Perly, Y., L. \& Minardi, I. (2003). Nutrição Animal. Editora Nobel.

Berry, W. D. \& Brake, J. (1985). Comparison of parameters associated with molt induced by fasting, zinc, and low dietary sodium in caged layers. Poultry Science, 64, 2027-2036.

Bertechini, A. G., Teixeira, A. S. \& Cerezer, C. E. (1995). Níveis de lisina para poedeiras comerciais leves na fase de pico de postura. Conferência APINCO de Ciência $e$ Tecnologia Avícolas. Fundação Apinco de Ciência e Tecnologia Avícolas Curitiba, Curitiba.

Bertechini, G. A. \& Geraldo, A. (2005). Conceitos modernos em muda forçada de poedeiras comerciais. In: Oeste, A. C. (ed.) VII Simpósio goiano de avicultura e II simpósio goiano de suinocultura. Goiânia.

Biggs, P. E., Douglas, M. W., Koelkebeck, K. W. \& Parsons, C. M. (2003). Evaluation of nonfeed removal methods for molting programs. Poultry Science, 82, 749-753.

Breeding, S. W., Brake, J., Garlich, J. D. \& Johnson, A. L. (1992). Molt induced by dietary zinc in a low-calcium diet. Poultry Science, 71, 168-180.

Calderon, V. M. \& Jensen, 1. S. (1990). The requirement for sulfur amino acid by laying 
hens as influenced by the protein concentration. Poultry Science, 69, 934-944.

Combs, G. F. (1964). Further studies of protein and amino acid needs of broilers and laying hens. Proceeding Maryland Nutrition Conference. Maryland.

Cotta, T. (1997). Reprodução da galinha e produção de ovos. Universidade Federal de Lavras, Lavras.

Dale, N. (1994). Proteína ideal para pollos de engorde. Avicultura Profesional, 11, 104-107.

Fernandes, E. D. A., Guarato, E. M. \& Murakami, A. (1983). Efeito da temperatura e do período de armazenamento sobre a qualidade interna de ovos para consumo. Informe Agropecuário, 9, 58-61.

Harms, R. H. \& Miles, R. D. (1988). Influence of Fermatco on the performance of laying hens when fed different methionine levels. Poultry Science, 67, 842-844.

Harms, R. H. \& Russell, G. B. (1993). Optimizing egg mass with amino acid supplementation of a low-protein diet. Poultry Science, 72, 1892-1896.

Hiramoto, K., Muramatsu, T. \& Okumura, J. (1990). Effect of methionine and lysine deficiencies on protein synthesis in the liver and oviduct and in the whole body of laying hens. Poultry Science, 69, 84-89.

Jardim Filho, R. M., Stringhini, J. H., Andrade, M. A., Café, M. B., Leandro, N. S. M. \& Carvalho, F. B. (2010). Níveis de lisina digestível para poedeiras Hy-Line W-36 em produção. Revista Brasileira de Zootecnia, 39, 787-795.

Kuenzel, W. J., Wideman, R. F., Chapman, M., Golden, C. \& Hooge, D. M. (2005). A practical method for induced moulting of caged layers that combines full access to feed and water, dietary thyroactive protein, and short day length. World's Poultry Science Journal, 61, 599-624.

Lana, G. R. Q., Silva Junior, R. G. C., Valerio, S. R., Lana, A. M. Q. \& Cordeiro, E. C. G. B. (2001). Efeito da densidade e de programas de alimentação sobre o desempenho de frangos de corte. Revista Brasileira de Zootecnia, 30, 1258-1265.
Leeson, S., Summers, J. D. \& Scott, M. L. (2001). Nutrition of the chicken, 4th ed. edn. Guelph University Books, Guelph.

Macari, M. \& Furlan, L. R. (1993). Mecanismos fisiológicos envolvidos na muda forçada. Curso de Fisiologia da reprodução das aves. Fundação APINCO, Campinas de Ciência e Tecnologia Avícolas.

Mateos, G. G. (1991). Nutrición y alimentación de gallinas ponedoras. De Blas, Barcelona.

Mendonça, B. P. (1996). Manejo alimentar de matrizes pesadas. In: APINCO (ed.) Anais da Conferência APINCO de Ciência $e$ Tecnologia Avícola. Curitiba.

Mendonça Jr, C. X. \& Lima, F. R. (1999). Efeito dos níveis de proteína e de metionina da dieta sobre o desempenho de galinhas poedeiras após a muda forçada. Brazilian Journal of Veterinary Research and Animal Science, 36, 332-338.

Nunes, R. V., Schneider, S. E., Souza, C., Sangali, C. P., Polese, C., Bueno, R. S., Vieites, F. M. Exigência de lisina digestível para poedeiras semi-pesadas de 50 a 66 semanas de idade. (2015). Arquivo Brasileiro de Medicina Veterinária e Zootecnia, 67, 1675-1683.

Parr, J. F. \& Summers, J. D. (1991). The effect of minimizing amino acid excesses in broiler diets. Poultry Science, 70, 1540-1549.

Pastore S. M., Gomes, P. C., Barreto, S. L. T., Viana, G. S., Silva, E. A., Almeida, R. L., Barbosa, L. V. S., Oliveira, W. P. (2015). Exigência nutricional de lisina digestível para galinhas poedeiras leves em produção. Ciência Rural, 45, 1496-1502.

Prochaska, J. F., Carey, J. B. \& Shafer, D. J. (1996). The effect of L-lysine intake on egg component yield and composition in laying hens. Poultry Science, 75, 1268-1277.

Rodrigueiro, R. J. B., Albino, L. F. T., Rostagno, H. S., Gomes, P. C., Pozza, P. C. \& Neme, R. (2000). Exigência de metionina+ cistina para frangos de corte na fase de crescimento e acabamento. Revista Brasileira de Zootecnia, 29, 507-517.

Roland, D. A. \& Brake, J. (1982). Influence of premolt production on postmolt performance with explanation for improvement in egg 
production due to force molting. Poultry Science, 61, 2473-2481.

Rostagno, H. S., Albino, L. F. T., Donzele, J. L., Gomes, P. C., Oliveira, R., Lopes, D. C., Ferreira, A. S., Barreto, S. \& Euclides, R. F. (2005). Composição de alimentos e exigências nutricionais, 2 edn. Universidade Federal de Viçosa, Viçosa.

Rostagno, H. S., Albino, L. F. T., Donzele, J. L., Gomes, P. C., Oliveira, R., Lopes, D. C., Ferreira, A. S., Barreto, S. \& Euclides, R. F. (2011). Composição de alimentos e exigências nutricionais, 3 edn. Universidade Federal de Viçosa, Viçosa.

Shafer, D. J., Carey, J. B. \& Prochaska, J. F. (1996). Effect of dietary methionine intake on egg component yield and composition. Poultry Science, 75, 1080-1085.

Silva, J. H. V. \& Santos, V. J. (2000). Efeito do carbonato de cálcio na qualidade da casca dos ovos durante a muda forçada. Revista Brasileira de Zootecnia, 29, 1440-1445.

Sohail, S. S., Bryant, M. M. \& Roland, D. A. (2002). Influence of supplemental lysine, isoleucine, threonine, tryptophan and total sulfur amino acids on egg weight of Hy-Line W-36 hens. Poultry Science, 81, 1038-1044.
Togashi, C. K., Fonseca, J. B., Soares, R. d. T. R. N. \& Souza, C. L. M. (2002). Determinação de níveis de metionina+ Cistina para poedeiras semi-pesadas alimentadas com rações contendo levedura seca (Saccharomyces cerevisiae). Revista Brasileira de Zootecnia, 31, 1426-1433.

Waldroup, P. W. \& Hellwig, H. M. (1995). Methionine and total sulfur amino acid requirements influenced by stage of production. The Journal of Applied Poultry Research, 4, 283-292.

Webster, A. B. (2003). Physiology and behavior of the hen during induced molt. Poultry Science, 82, 992-1002.

Recebido em Fevereiro 16, 2016

Aceito em Março 4, 2016

License information: This is an open-access article distributed under the terms of the Creative Commons Attribution License, which permits unrestricted use, distribution, and reproduction in any medium, provided the original work is properly cited 